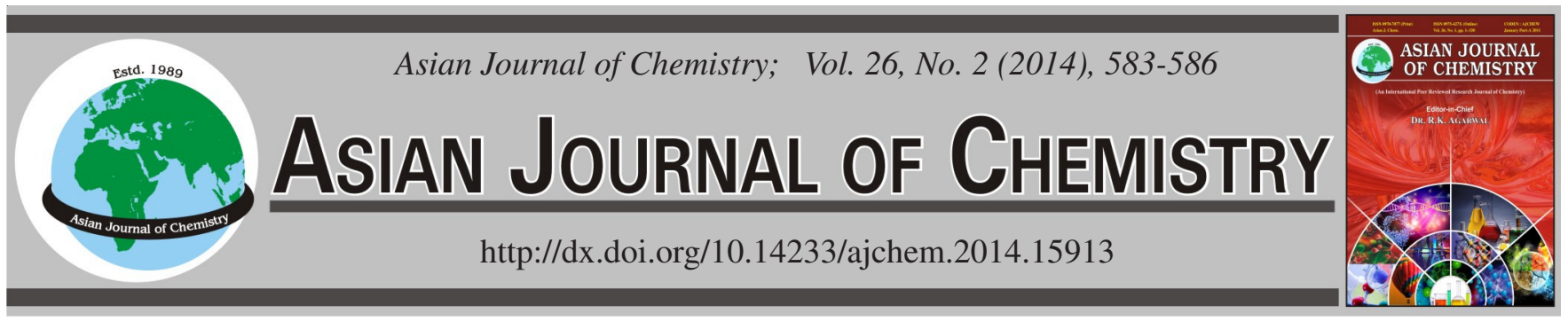

\title{
Enhanced Luminescent Properties of Europium Complex by Replacement of Water Molecules by 1,10-Phenanthroline
}

\author{
Rajesh Kumar, Rajni Arora, V.B. Taxak, Dayawati and S.P. Khatkar*
}

Department of Chemistry Maharshi Dayanand University, Rohtak-124 001, India

*Corresponding author: E-mail: s_khatkar@ rediffmail.com

Received: 14 June 2013;

Accepted: 30 September 2013;

Published online: 15 January 2014;

AJC-14592

The complex $\left[\mathrm{Eu}(\mathrm{L})_{3}(\mathrm{phen})\right]$ (where $\mathrm{L}=2^{\prime}$-hydroxy-4'-methoxy-2-phenylacetophenone, phen = 1,10-phenanthroline) was synthesized and characterized, by elemental analysis, energy dispersive X-ray spectroscopy, ${ }^{1} \mathrm{H}$ NMR spectroscopy infra red spectroscopy, TGA/ DTA, scanning electron microscopy and the excitation as well as emission spectrum. The $\left[\mathrm{Eu}(\mathrm{L})_{3}(\right.$ phen $\left.)\right]$ had regular shaped particles with size less than $1 \mu \mathrm{m}$ without any phase separation and on excitation at $344 \mathrm{~nm}$ emits bright red luminescence with main peak at $614 \mathrm{~nm}$. The complex emitting red luminescence might be used to make the electroluminescent devices for display purposes.

Keywords: $\mathrm{Eu}^{3+}$, Infrared, ${ }^{1} \mathrm{H}$ NMR, Elemental analysis, Luminescence.

\section{INTRODUCTION}

The structural tuning of lanthanide complexes as efficient light-conversion devices has become an important pursuit to researchers due to their excellent luminescence properties ${ }^{1-6}$. The excellent luminescence of organic-metal complexes is due to energy transfer from organic ligand to central metal ion by "antenna effect", which can increase the luminescence efficiency. The $\beta$-diketones are excellent organic molecules to transfer energy to lanthanide ions ${ }^{7,8}$. The europium doped phosphors may show many emission lines which correspond to transitions from the ${ }^{5} \mathrm{D}_{0}, 1,2,3$ excited states to the ${ }^{7} \mathrm{~F}_{\mathrm{J}}$ ( where $\mathrm{j}=0,1,2,3$ ) ground states of $\mathrm{Eu}^{3+}$, such as ${ }^{5} \mathrm{D}_{3} \rightarrow{ }^{7} \mathrm{~F}_{1}(421 \mathrm{~nm}),{ }^{5} \mathrm{D}_{3} \rightarrow{ }^{7} \mathrm{~F}_{2}$ $(431 \mathrm{~nm}),{ }^{5} \mathrm{D}_{3} \rightarrow{ }^{7} \mathrm{~F}_{3}(456 \mathrm{~nm}),{ }^{5} \mathrm{D}_{2} \rightarrow{ }^{7} \mathrm{~F}_{0}(471 \mathrm{~nm}),{ }^{5} \mathrm{D}_{2} \rightarrow{ }^{7} \mathrm{~F}_{2}$ $(498 \mathrm{~nm}),{ }^{5} \mathrm{D}_{2} \rightarrow{ }^{7} \mathrm{~F}_{3}(518 \mathrm{~nm}),{ }^{5} \mathrm{D}_{1} \rightarrow{ }^{7} \mathrm{~F}_{1}(539 \mathrm{~nm}),{ }^{5} \mathrm{D}_{1} \rightarrow{ }^{7} \mathrm{~F}_{2}$ $(560 \mathrm{~nm}),{ }^{5} \mathrm{D}_{0} \rightarrow{ }^{7} \mathrm{~F}_{0}(578 \mathrm{~nm}),{ }^{5} \mathrm{D}_{0} \rightarrow{ }^{7} \mathrm{~F}_{1}(591 \mathrm{~nm}),{ }^{5} \mathrm{D}_{0} \rightarrow{ }^{7} \mathrm{~F}_{2}$ $(613 \mathrm{~nm}),{ }^{5} \mathrm{D}_{0} \rightarrow{ }^{7} \mathrm{~F}_{3}(656 \mathrm{~nm})$ and ${ }^{5} \mathrm{D}_{0} \rightarrow{ }^{7} \mathrm{~F}_{4}(698 \mathrm{~nm})^{9,10}$. The europium complexes mainly involve five narrow emission lines, corresponding to ${ }^{5} \mathrm{D}_{0} \rightarrow{ }^{7} \mathrm{~F}_{\mathrm{j}}$ transitions, where $\mathrm{j}=0,1,2$, 3 and 4 emitting at 578, 591, 610, 651 and $702 \mathrm{~nm}$ respectively; ${ }^{5} \mathrm{D}_{0} \rightarrow{ }^{7} \mathrm{~F}_{2}$ being the strongest with red emission of high color purity ${ }^{11,12}$. In recent years organic electroluminescent materials have been prepared representing a low cost fabrication route and low voltage operation for large area light display technology and large flat panel display ${ }^{13,14}$. The rare earth ions with organic ligands have been doped in polymers for optical amplification ${ }^{15,16}$. However, in recent years organic electroluminescent materials/complexes have been prepared representing a low cost fabrication route and low voltage operation for large area light display technology and large flat panel display ${ }^{17}$. Organic light emitting diode displays offer the thinnest profile of any color flat panel technology. The whole assembly can be very small as little as $2 \mathrm{~mm}$ in depth that can replace the heavy and bulky cathode-ray tube of the display systems. Now-a-days, organic luminescent materials are used commercially for example in laptop computers, mobile phones, car dashboards, advertisement panels and decorating lighting, etc.

In present work the complex $[\mathrm{Eu}(\mathrm{L}) 3($ phen) $]$ (where $\mathrm{L}=$ 2'-hydroxy-4'-methoxy-2-phenylacetophenone, phen $=1,10$ phenanthroline) was synthesized and characterized by elemental analysis, energy dispersive X-ray spectroscopy, ${ }^{1} \mathrm{H}$ NMR spectroscopy, infra red spectroscopy, TGA/DTA, scanning electron microscopy and the excitation as well as emission spectrum. The complex emitting red luminescent might be used to make the electroluminescent devices.

\section{EXPERIMENTAL}

Resorcinol (99\%), benzyl cyanide (99\%), sodium hydroxide (99.9\%), 1,10-phenanthroline (99\%), Eu( $\left.\mathrm{NO}_{3}\right)_{3} \cdot \mathrm{xH}_{2} \mathrm{O}$ $(99.99 \%)$ were purchased from Aldrich. All chemicals were used without further purification.

Synthesis of ligand: 2'-Hydroxy-4'-methoxy-2-phenylacetophenone was synthesized according to the method sited in literature ${ }^{18}$ and recrystalized three times from ethanol.

Synthesis of complex: The complex $\left[\mathrm{Eu}(\mathrm{L})_{3}(\right.$ phen)] was prepared by mixing alcoholic solutions of 2'-hydroxy-4'methoxy-2-phenylacetophenone (L) and phen with an aqueous 
solution of $\mathrm{Eu}\left(\mathrm{NO}_{3}\right)_{3} \cdot \mathrm{xH}_{2} \mathrm{O}$ in 3:1:1 molar ratio with constant stirring on magnetic stirrer. The $\mathrm{pH}$ of mixture was adjusted to 7 with $0.05 \mathrm{M} \mathrm{NaOH}$ solution. This resulted into formation of white precipitates. These precipitates were stirred for $3 \mathrm{~h}$ at $40{ }^{\circ} \mathrm{C}$ and then allowed to stand for $1 \mathrm{~h}$. The precipitates were filtered, washed with water and ethanol, dried in air and then vacuum desiccator.

Measurements: The elemental analysis was performed on the Perkin Elmer 2400 elemental analyzer, energy dispersive X-ray spectroscopy of the complex was performed by EDS, PV99. ${ }^{1} \mathrm{H}$ NMR spectrum was recorded on Bruker Avance 300 spectrometer $(300 \mathrm{MHz}$ ) using chloroform $\left(\mathrm{CDCl}_{3}\right)$ as solvent, infrared spectrum $\left(4000-400 \mathrm{~cm}^{-1}\right)$ was recorded with Perkin Elmer spectrum RX-I FT infrared spectrophotometer, thermal analysis was carried out by using simultaneous thermal analyzer (STA; Scinco, STA S-1500) with heating rate of $5{ }^{\circ} \mathrm{C} / \mathrm{min}$, scanning electron microscopy of the complex was performed by JEOL JSM-6510 scanning electron microscope operating at $10 \mathrm{Kv}$. The excitation and emission spectra were recorded by using HITACHI F-7000 fluorescence spectrophotometer. Photoluminescence intensity was recorded with spectroradiometer CS-1000.

\section{RESULTS AND DISCUSSION}

Solubility of the synthesized complex was checked in various organic solvents. The complex was found to be soluble in dimethyl sulfoxide, dimethyl formamide, chloroform and acetone, sparingly soluble in methanol, ethanol and ethyl acetate but insoluble in benzene and toluene.

Elemental analysis: Elemental analytical data for the complex: $\mathrm{C} \%$ found $=64.48($ Calc. $=64.83), \mathrm{H} \%$ found $=$ 4.53 (calc. $=4.46)$ and $\mathrm{N} \%$ found $=2.62($ calc. $=2.65)$ indicated that the stoichiometry of the complex to be $1: 3: 1$ (europium: ligand: co-ligand).

Energy dispersive X-ray spectroscopy (EDS): The chemical formula of the prepared complex was also confirmed by energy dispersive X-ray spectroscopy (EDS). The EDS spectrum shown in Fig. 1 and percentage of various elements after calculations was, $\mathrm{C} \%$ found $=64.39$ (calc. $=64.83)$, $\mathrm{O} \%$ found $=14.02($ calc. $=13.65)$ and $\mathrm{Eu} \%$ found $=14.23$ (calc. $=14.41)$.

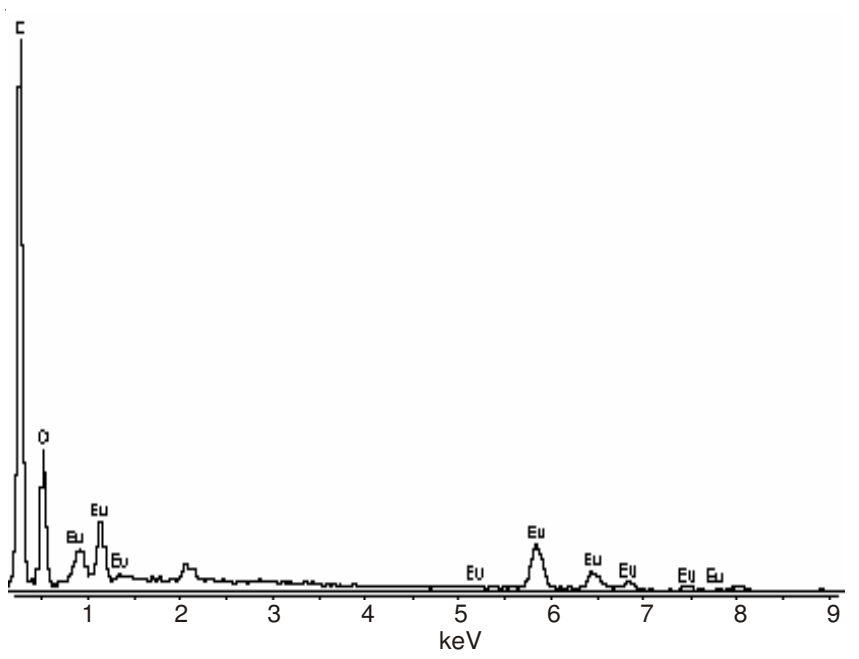

Fig. 1. EDS spectrum of $\left[\mathrm{Eu}(\mathrm{L})_{3}(\mathrm{phen})\right]$
${ }^{1}$ H NMR spectrum: All chemical shifts are given in ppm with respect to tetramethylsilane (TMS). Values for various ${ }^{1} \mathrm{H}$ NMR chemical shifts are $3.87\left(\mathrm{~s}, 9 \mathrm{H}, 3-\mathrm{OCH}_{3}\right)$ 6.9-7.2 (bs, $3 \mathrm{H},-\mathrm{CH}=$ ), 7.30-7.76 (m, 8H, Aromatic), 7.82-8.14 (m, 2H, Aromatic), 8.30-9.57 (bm, 20H Aromatic), 10.12-10.15 (d, 2H, Aromatic).

Infrared spectroscopy: The infrared spectrum of ligand showed the characteristic stretching peak at $1638 \mathrm{~cm}^{-1}$ due to $\mathrm{C}=\mathrm{O}$ group of the 2'-hydroxy-4'-methoxy-2-phenylacetophenone (L) disappeared in the complex which indicated that the $\mathrm{C}=\mathrm{O}$ group of the $\mathrm{L}$ participated in coordination with $\mathrm{Eu}^{3+}$ ions. The appearance of new peak at $1609 \mathrm{~cm}^{-1}$ in complex assigned to $\mathrm{C}=\mathrm{C}$ stretching mode indicated that the $\mathrm{L}$ coordinated with $\mathrm{Eu}^{3+}$ ions in enolic form. The peak for $\mathrm{Ph}-\mathrm{O}$ vibration $(\mathrm{Ph}=$ phenyl $)$ at $1262 \mathrm{~cm}^{-1}$ in free $\mathrm{L}$ shifted to 1222 $\mathrm{cm}^{-1}$ in the complex which indicate that the $\mathrm{Ph}-\mathrm{O}$ group coordinated with $\mathrm{Eu}^{3+}$ ions. The shift of $\mathrm{C}-\mathrm{N}$ vibration mode of phen from $1406 \mathrm{~cm}^{-1}$ to $1390 \mathrm{~cm}^{-1}$ in complex and the benzene ring $\mathrm{C}-\mathrm{H}$ bending vibration peaks of phen in high frequency region appearing at 864 and $739 \mathrm{~cm}^{-1}$ are shifted to 843 and $727 \mathrm{~cm}^{-1}$, indicating that the chemical bonds are formed between $\mathrm{Eu}^{3+}$ ion and nitrogen atoms of phen. The bands $1411 \mathrm{~cm}^{-1}$ and $1452 \mathrm{~cm}^{-1}, 1494 \mathrm{~cm}^{-1}$ were assigned to C-C skeletal vibrational stretching of aromatic ring. Finally, the absorption peak at about $431 \mathrm{~cm}^{-1}$ in complex can be assigned to the Eu-O vibration absorption band ${ }^{19}$. Overall, the results indicated that phen coordinated with the $\mathrm{Eu}^{3+}$ ions through nitrogen while $\mathrm{L}$ coordinated with the $\mathrm{Eu}^{3+}$ ions through enolic and phenolic oxygen as shown in Fig. 2.

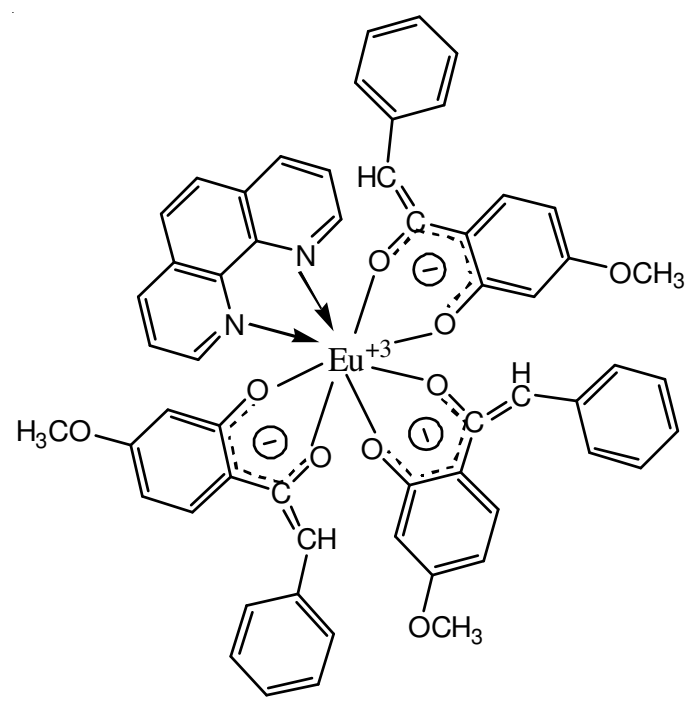

Fig. 2. Structure of $\left[\mathrm{Eu}(\mathrm{L})_{3}\right.$ (phen)]

Thermal stability: The TGA/DTA curves of the complex (Fig. 3) show weight loss at about $215^{\circ} \mathrm{C}$ is due to elimination of phen and the weight loss at about $520^{\circ} \mathrm{C}$ is due to elimination or decomposition of L. However, above $520{ }^{\circ} \mathrm{C}$ the complex $\left[\mathrm{Eu}(\mathrm{L})_{3}(\right.$ phen $\left.)\right]$ completely decomposed.

Scanning electron micrograph: The surface morphological features (shape and particle size) of the powder complex were studied by scanning electron microscopy. The instrumental parameters, accelerating voltage, spot size, magnification and working distance are indicated in the scanning electron 


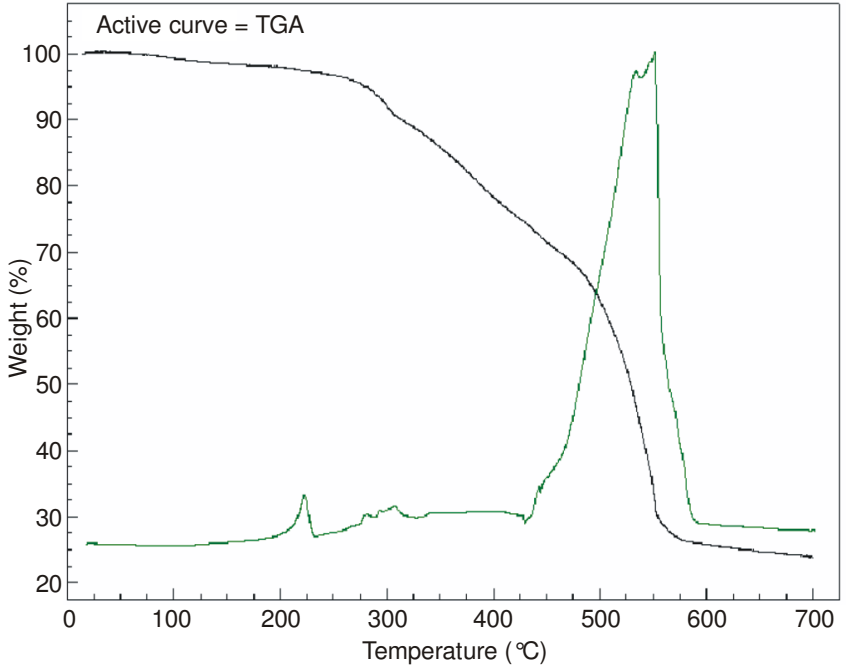

Fig. 3. TGA/DTA curves of $\left[\mathrm{Eu}(\mathrm{L})_{3}(\mathrm{phen})\right]$

micrograph image (Fig. 4). The scanning electron micrographs for the complex showed that the material obtained had regular shaped particles with size less than $1 \mu \mathrm{m}$ without any phase separations. The complex may facilitate the future applications with good optical properties.

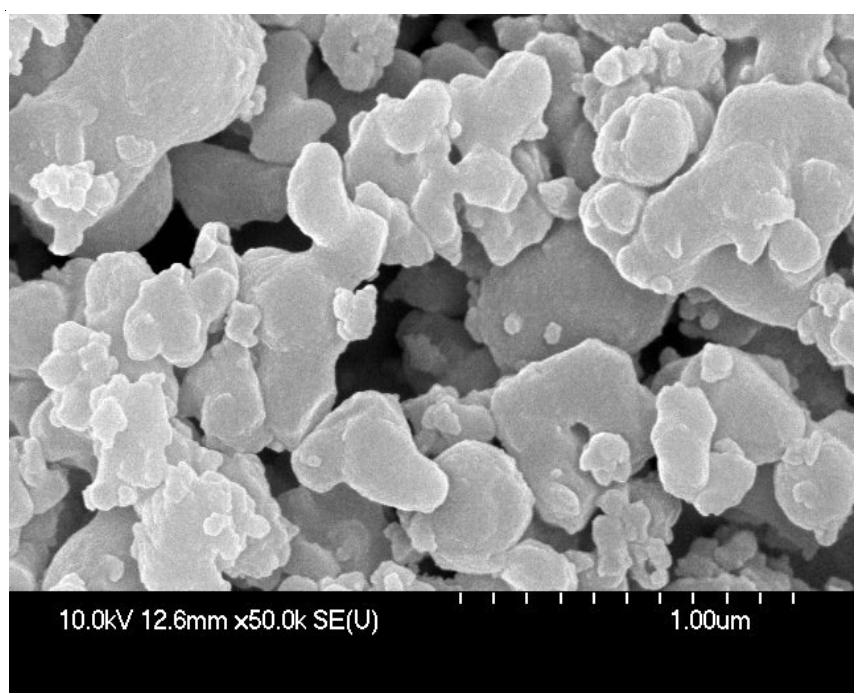

Fig. 4. Scanning electron micrograph image of $\left[\mathrm{Eu}(\mathrm{L})_{3}(\mathrm{phen})\right]$

Excitation and emission spectra: The excitation spectrum of complex shown in Fig. 5a was recorded at room temperature by using HITACHI F-7000 fluorescence spectrophotometer inspecting at $614 \mathrm{~nm}$ consists of two peaks one at $344 \mathrm{~nm}$ assigned to excitation of $\mathrm{L}$ and another at 372 assigned to excitation of phen. However, the energy position of the maximum excitation in complex is different from the maximum excitation of free L (at $353 \mathrm{~nm}$ ) Fig. $5 \mathrm{~b}$ and free phen (at $377 \mathrm{~nm}$ ) Fig. 5c, indicating that coordination of $\mathrm{L}$ as well as phen with $\mathrm{Eu}^{3+}$ ions in the complex ${ }^{20}$. The emission spectrum of complex is shown in Fig. 6 was recorded at room temperature on excitation at $344 \mathrm{~nm}$. The emission spectrum of $\left[\mathrm{Eu}(\mathrm{L})_{3}(\mathrm{phen})\right]$ consists of eight peaks which are due to the transitions $\left({ }^{5} \mathrm{D}_{3} \rightarrow{ }^{7} \mathrm{~F}_{1}\right)$ at $421 \mathrm{~nm},\left({ }^{5} \mathrm{D}_{3} \rightarrow{ }^{7} \mathrm{~F}_{3}\right)$ at $453 \mathrm{~nm},\left({ }^{5} \mathrm{D}_{2} \rightarrow{ }^{7} \mathrm{~F}_{1}\right)$ at $489 \mathrm{~nm}$, $\left({ }^{5} \mathrm{D}_{0} \rightarrow{ }^{7} \mathrm{~F}_{0}\right)$ at $580 \mathrm{~nm},\left({ }^{5} \mathrm{D}_{0} \rightarrow{ }^{7} \mathrm{~F}_{1}\right)$ at $591 \mathrm{~nm},\left({ }^{5} \mathrm{D}_{0} \rightarrow{ }^{7} \mathrm{~F}_{2}\right)$ at $614 \mathrm{~nm}$, $\left({ }^{5} \mathrm{D}_{0} \rightarrow{ }^{7} \mathrm{~F}_{3}\right)$ at $651 \mathrm{~nm}$ and $\left({ }^{5} \mathrm{D}_{0} \rightarrow{ }^{7} \mathrm{~F}_{4}\right)$ at $704 \mathrm{~nm}$. Among these,
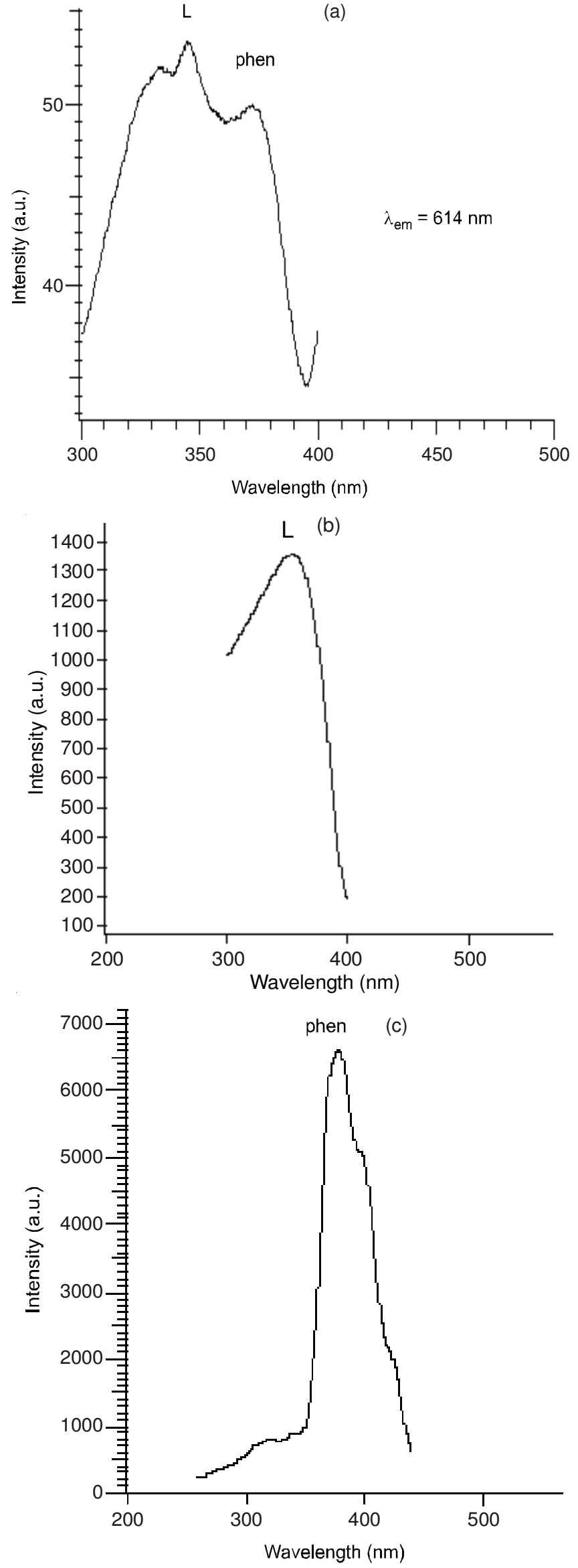

Fig. 5. (a) Excitation spectrum of $\left[\mathrm{Eu}(\mathrm{L})_{3}(\mathrm{phen})\right]$; (b) Excitation spectrum of L; (c) Excitation spectrum of Phen 
the emission at $614 \mathrm{~nm}$ from the ${ }^{5} \mathrm{D}_{0} \rightarrow{ }^{7} \mathrm{~F}_{2}$ electronic transition is the strongest and in agreement with the low symmetry around the $\mathrm{Eu}^{3+}$ ion $^{21}$. The intensity of peaks results by transitions ${ }^{5} \mathrm{D}_{3} \rightarrow{ }^{7} \mathrm{~F}_{1,3}$ and ${ }^{5} \mathrm{D}_{2} \rightarrow{ }^{7} \mathrm{~F}_{1}$ is less due to competitive non-radiative internal relaxation of from higher ${ }^{5} \mathrm{D}_{3,2,1}$ levels to lower ${ }^{5} \mathrm{D}_{0}$ energy level. The emission color has been analyzed with help of the Commission Internationale de Eclairage chromaticity coordinate diagram. The colour coordinates of the complex are found to be $\mathrm{x}=0.6045$ and $\mathrm{y}=0.3127$ indicating a bright red photolumi nescent material. The photoluminescence intensity of the complex is $63.34 \mathrm{~cd} / \mathrm{m}^{2}$. The complex thus having bright red emis sion and good photoluminescence intensity might be promisingly applicable for various display applications. The present europium complex has better photoluminescent intensity $\left(63.34 \mathrm{~cd} / \mathrm{m}^{2}\right)$ than earlier reported complexes $\mathrm{Eu}\left(\mathrm{L}_{1}\right)_{3} \cdot 2 \mathrm{H}_{2} \mathrm{O}\left(61.17 \mathrm{~cd} / \mathrm{m}^{2}\right)$, where $\mathrm{L}_{1}=2$ '-hydroxy-4'methoxy-2-phenylacetophenone, $\mathrm{Eu}\left(\mathrm{L}_{2}\right)_{3} \cdot 2 \mathrm{H}_{2} \mathrm{O}\left(62.87 \mathrm{~cd} / \mathrm{m}^{2}\right)$ where $\mathrm{L}_{2}=2^{\prime}$-hydroxy-4'-methoxy-2-( $p$-methoxyphenyl) acetophenone, $\mathrm{Eu}\left(\mathrm{L}_{3}\right)_{3} \cdot 2 \mathrm{H}_{2} \mathrm{O}\left(61.83 \mathrm{~cd} / \mathrm{m}^{2}\right)$, where $\mathrm{L}_{3}=2^{\prime}$-hydroxy-4',6'-dimethoxy-2-phenylacetophenone, $\mathrm{Eu}\left(\mathrm{L}_{4}\right)_{3} \cdot 2 \mathrm{H}_{2} \mathrm{O}$ $\left(62.06 \mathrm{~cd} / \mathrm{m}^{2}\right)$, where $\mathrm{L}_{4}=2$ '-hydroxy-4',6'-dimethoxy-2- $(p$ methoxy-phenyl) acetophenone ${ }^{3}$ and $\mathrm{Eu}(\mathrm{TNB})_{3} \cdot$ phen, where TNB $=$ 4,4,4-trifluoro-1-(2-naphthyl)-1,3-butanedione and phen $=1,10$-phenanthroline ${ }^{8}$.

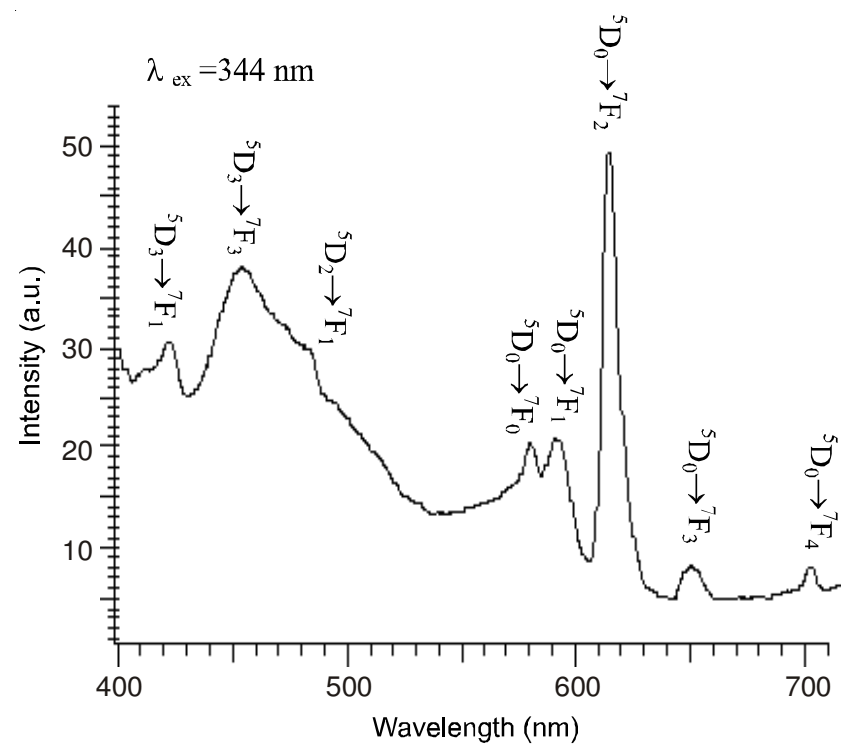

Fig. 6. Emission spectrum of $\left[\mathrm{Eu}(\mathrm{L})_{3}(\mathrm{phen})\right]$

\section{Conclusion}

The europium complex, $\left[\mathrm{Eu}(\mathrm{L})_{3}(\mathrm{phen})\right]$ have been synthesized. The synthesized complex is electroneutral molecule, in which the each central europium ion is wrapped with three $\mathrm{L}$ molecules and one phen molecule. The L excites $\mathrm{Eu}^{3+}$ luminescence efficiently. The replacement of two water molecules by one phen molecule increases the luminescence intensity and thermal stability of complex. The europium complex $\left[\left[\mathrm{Eu}(\mathrm{L})_{3}(\right.\right.$ phen $\left.)\right]$ emits very strong red characteristics emission of $\mathrm{Eu}^{3+}$ in solid states at room temperature. The color coordinates of $\left[\mathrm{Eu}(\mathrm{L})_{3}(\mathrm{phen})\right]$ complex fall in red region $(\mathrm{x}=0.6045$ and $y=0.3127)$. The complex having bright red luminescence and good photoluminescence intensity $\left(63.34 \mathrm{~cd} / \mathrm{m}^{2}\right) \mathrm{might}$ be promisingly applicable for various display applications.

\section{ACKNOWLEDGEMENTS}

The authors expressed their profound thanks to University Grant Commission, New Delhi for providing financial assistance in the form of a UGC-BSR Research Start-Up-Grant No. F.20-4(5)/2012(BSR).

\section{REFERENCES}

1. S.A. Junior, F.V. de Almeida, G.F. de Sá and C. de Mello Donegá, J. Lumin., 72-74, 478 (1997).

2. R. Kumar, J.K. Makrandi, I. Singh and S.P. Khatkar, Spectrochim. Acta A, 69, 1119 (2008).

3. R. Kumar, J.K. Makrandi, I. Singh and S.P. Khatkar, J. Lumin., 128, 1297 (2008).

4. R. Kumar, S.P. Khatkar, J.K. Makrandi and I. Singh, Electrochem. Soc. Trans., 11, 29 (2008).

5. R. Kumar, S.P. Khatkar, J.K. Makrandi and I. Singh, Electrochem. Soc. Trans., 11, 11 (2008).

6. R. Kumar, J.K. Makrandi, V.B. Taxak and S.P. Khatkar, Electrochem. Soc. Trans., 6, 25 (2008).

7. A.A.S. Araújo, H.F. Brito, O.L. Malta, J.R. Matos, E.E.S. Teotonio, S. Storpirtis and C.M.S. Izumi, J. Inorg. Biochem., 88, 87 (2002).

8. S.P. Khatkar, S.D. Han, J.Y. Park, R. Kumar, Y. Liang and V.B. Taxak, Bull. Electrochem., 21, 123 (2005).

9. Z. Yang, J. Tian, S. Wang, G. Yang, X. Li and P. Li, Mater. Lett., 62, 1369 (2008).

10. X.Q. Su and B. Yan, J. Alloys Comp., 421, 273 (2006).

11. T. Jin, S. Tsutsumi, Y. Deguchi, K. Machida and G. Adachi, J. Alloys Comp., 252, 59 (1997).

12. B.L. An, M.L. Gong, K.W. Cheah, J.M. Zhang and K.F. Li, Chem. Phys. Lett., 385, 345 (2004).

13. C. Pettinari, F. Marchetti, A. Cingolani, A. Drozdov, I. Timokhin, S.I. Troyanov, V. Tsaryuk and V. Zolin, Inorg. Chim. Acta, 357, 4181 (2004).

14. J. Moynagh and H. Schimmel, Nature, 400, 105 (1999).

15. L.H. Slooff, A. Polman, S.I. Klink, G.A. Hebbink, L. Grave, F.C.J.M. van Veggel, D.N. Reinhoudt and J.W. Hofstraat, Opt. Mater., 14, 101 (2000).

16. D. An, Z. Yue and R.T. Chen, Appl. Phys. Lett., 72, 2806 (1998).

17. R.H. Friend, R.W. Gymer, A.B. Holmes, J.H. Burroughes, R.N. Marks, C. Taliani, D.D.C. Bradley, D.A.D. Santos, J.L. Brdas, M. Lgdlund and W.R. Salaneck, Nature, 397, 121 (1999).

18. G.G. Badcock, G.W.K. Cavill, A. Robertson and W.B. Whalley, J. Chem. Soc., 2961 (1950).

19. G. Xiao-hua, P. Xi, S. Xin-yuan and C. Bo-wen, Polymer (Korea), 32 , 305 (2008).

20. A.O. Ribeiro, P.S. Calefi, A.M. Pires and O.A. Serra, J. Alloys Comp., 374, 151 (2004).

21. C.R. De Silva, J. Wang, M.D. Carducci, S. Asha Rajapakshe and Z. Zheng, Inorg. Chim. Acta, 357, 630 (2004). 